\title{
Certificate Of Online Learning And Teaching (COLT) At The University Of Hawaii: A Horse Of Another Color For Earning College Credits
}

Michael P. Menchaca, University of Hawaii at Manoa, USA

Ellen S. Hoffman, University of Hawaii at Manoa, USA

\begin{abstract}
Current conventional wisdom may perceive that higher education is outdated and maybe even likely to collapse. Online education is often predicted to replace brick-and-mortar campuses with systems providing students access to world-class learning via smartphones and tablets. Many private and commercial ventures are embracing such concepts. However, in the race to implement large-scale models, significant key elements such as understanding that learning can be social, affective, personal, and even cultural may be missing. Thus, creative yet research-based programs at the university level are needed. While it is true that existing university structures might inhibit the implementation of radical programs, there are opportunities where such innovation can be offered. In the case of the Department of Educational Technology at the University of Hawaii, an option for a program at the certificate level not necessarily leading to a traditional degree was provided. The certificate option provided an opportunity to explore entrepreneurial models while also incorporating what we understand about learning, the brain, and newer technologies. This paper describes the circumstances and approach that led to the creation of an innovative program that still fit within current university structures.
\end{abstract}

Keywords: Higher Education; Online Learning; Adult Learning

\section{INTRODUCTION}

nyone reading recent headlines about higher education in the popular press would think that higher education is going the way of the dinosaurs (Christensen, Horn, \& Johnson, 2008). Online education is being touted as the new wave that will sweep away brick-and-mortar campuses, and finally end the tyranny of the lecture-test mentality established by out-of-touch faculty that is seen as dominating college classrooms. A new digital generation is predicted to be more willing to take their smartphones and tablets anywhere, anytime to access learning on their own terms and presumably at a much lower cost.

Much of this heavy-handed hype is coming not from current students and faculty, but from outside of higher education. Some of this is fueled by new enterprises hoping to capitalize on the $\$ 446$ billion industry that is higher education (Center for Excellence in Higher Education, n.d.). In fact, venture capitalists invested $\$ 429$ million in educational technology companies in 2011 alone on the premise that a new wave of online learning models will prove highly profitable as the old guard of higher education collapses in the digital era (Desantis, 2012). Who would want to go to the local campus on a set schedule when they can get videos of lectures from the greatest minds from such places as Harvard, Stanford, or the Massachusetts Institute of Technology (MIT)? Or maybe the excitement of high-end gaming and immersive virtual worlds is the lure, particularly when produced by the next Stephen Spielberg of the education-as-entertainment world. 
Not everyone arguing against traditional higher education is approaching the concept with a dollar sign in mind (Anderson, Boyles, \& Rainie, 2012). Some with stronger links to the academy have proposed that highly open courses and freely available web resources could promote personal learning environments (PLEs) where thoughtful students will be able to pick and choose among their interests and goals to obtain a world-class education. Students would be able to learn at their own pace, unlike the highly structured courses now provided by higher education. Further, as they examine topics of interest, each could pursue those aspects of a field that provide the most personal satisfaction and meets individual needs for fulfillment and career advancement.

While many models of disruption and proposed reform are being put forward that provide novel views of the future, we would argue that there are a number of more down-to-earth rationales that suggest such scenarios are possible but will not replace the formal learning of the university as proposed. Although the future may allow more options than are currently available to meet growing demands for the life-long learning needed in a knowledge society, the traditional university will still hold a major role in postsecondary education. In this paper, we will look at the reasons for such a stance, as well as provide an example of an entrepreneurial venture within a traditional institution that shows how new models can be developed and explored that provide the best of distance learning and formal classrooms. This paper first explores some of the issues about learning and community not fully a part of currently popularized models for distance education such as Massive Open Online Courses (MOOCs), then looks at a new program at the University of Hawaii at Manoa that is attempting to meld flexibility, individual needs, and understanding of student learning with new technologies in the context of traditional semesters and credit-hour course production.

\section{HOW STUDENTS LEARN AS THE CENTER OF REFORM}

Educational research is not always carefully examined in setting policy for public education, but the vast studies about how students learn best and what kinds of teaching make a difference in student outcomes suggest that the future models proposed are missing some key elements.

First, much of the research finds that learning is a social process, so that the idea of students sitting passively watching world-class lectures meets only part of the learning equation (Willingham, 2009). In fact, the best learning comes from doing, with active learning and real-world problems producing deeper learning on a topic as well as ensuring the learning will be sustained. This relates to the second observation, that learning is both a cognitive and affective process. Exposure to content alone is unlikely to sustain engagement. In fact, many students fail to complete courses in distance education because of the focus on content over process and because the social interaction that are well understood from the face-to-face classroom are missing (Abrami, Bernard, Bures, Borokhovski, \& Tamim, 2011). Students consistently indicate that collaboration with peers is key to successful learning environments, regardless of context (Menchaca \& Bekele, 2008).

At the same time, knowledge of adult learning suggests there is a need for content that meets personal needs, recognizes the learner as bringing knowledge that needs to be applied within the learning context, and has the flexibility to deal with students' diverse personal schedules and learning styles (Merriam, 2008). Further, unguided instruction has been shown to be a poor method for providing support. While this argues against rigid course structures, it also suggests that options that guide students to increase their expertise and sustain their attention may be more important than having a massive palette of choices and little assistance in figuring out which is the best fit. This includes the place of an instructor who can monitor student action and understand how to help students in gaining content knowledge.

Finally, mass education as proposed by some of the reform models lacks understanding of local needs, something many public higher education institutions (and some privates) were designed to meet. Putting learning in a context that shows how knowledge can be used in one's own locus of control, and placing students in groups with others to build local communities of practice can have positive impacts for both the individuals involved and the locales where they reside. This puts learning in context that is meaningful and with individuals who are more likely to have shared interests and related goals. 


\section{AN ENTREPRENEURIAL MODEL FOR NEW PROGRAMS}

While existing structures within higher education might limit the freedom to implement programs with radically different delivery models, there do still exist opportunities for innovative and entrepreneurial models. The structure of existing degree programs at the University of Hawaii (UH) can be constraining when considering new models for teaching. Anything other than minor considerations must take into account complex requirements that govern operation including department, college, and university rules; accreditation requirements from multiple institutions; and the overall needs of the professional field.

However, within the existing structure, there does exist a model that while not leading to a full degree provides opportunity for innovation. Graduate programs at the university can offer graduate-level certificates organized around areas of need. Additionally, these programs can be delivered through the extension arm of the university, thus generating funds for the department, college, and university. Further, certificate programs can "double dip" and students can use courses taken toward completion of the certificate as electives in other advanced programs, including at the master's or doctoral level. Finally, certificates provide the opportunity for more creative and experimental content and delivery tied to the contemporary needs of the field. Electives and certificate courses are less constrained by rigid academic and accrediting requirements because those requirements are generally fulfilled within programmatic required core courses.

So, while very much still a part of the regular college program offerings provided at the university, the certificate program can also be entrepreneurial in design and delivery. Since certificate courses either fall within a category of not leading to a full degree or are utilized only as electives beyond specific degree requirements, they can fit within regular programs yet still differ substantially.

In the case of the Department of Educational Technology at UH, a program with a set of courses providing content tied to the burgeoning area of distributed learning while simultaneously serving as a model for innovative delivery of that very content was desired. Moreover, such a program needed to serve the specific needs of the workforce in the Hawaiian region. Hawaii is unique in that the main university campus for most graduate programs exists on a single island within a chain of multiple islands. Traditionally, students desiring higher levels of education have had to move from their homes in order to pursue additional education. In a culture where extended family plays a significant role in life decisions, the physical limitations of distance and the paucity of advanced degree choices for outer island students has significantly limited their opportunities for enrichment. Additionally, the nature of educational delivery itself has evolved and there is greater need for a workforce knowledgeable in online learning at all levels.

\section{THE COLT GOALS: MEETING LOCAL AND INDIVIDUAL NEEDS}

In order to address the unique challenges of the Hawaiian region, a program needed to be designed providing a structure consistent with the rules of the university and its accrediting bodies while also providing maximum choice and flexibility for students. Thus, recognizing that newer structures are needed to meet adult learning needs in the digital age, a new program at the University of Hawaii at Manoa (UHM) was developed that combines flexibility, choice and efficiency with structure and model pedagogies. The graduate Certificate in Online Learning and Teaching (COLT) applies concepts of personal learning, new social and multimedia technologies, distance learning options, and individual choice with more traditional course elements to provide a program that will meet important learning goals and ensure that students who begin the program also finish it.

The program's genesis grew from specific local needs in the state. As mentioned, there is a critical need in Hawaii for educators skilled in online education. Online education is projected to grow significantly. Although the majority of students today take nearly all of their courses in physical classrooms, market analysts predict that by 2014, the majority will learn in hybrid environments with significant online components (Adkins, 2009).

The initial impetus for development of the Certificate in Online Learning and Teaching came from a request by the Hawaii Department of Education (DOE) for a program to support their teachers who were involved in the virtual high school program in 2008. The Hawaii Online Task Force created the Hawaii Virtual Learning 
Network (HVLN) to expand and systematize online courses by offering a wide array of online courses to Hawaii's students. Further, their goal was for all DOE teachers to obtain additional training in e-learning, whether to teach fully online or to supplement traditional face-to-face class time.

However, the need is not limited to the K-12 professional segment, as there are increased calls for online learning, both stand-alone and supplemental (hybrid) throughout the educational community. For example, federal regulations and policy are moving towards requiring competence in e-learning for all new teachers, as documented in the National Technology Plan (U.S. Department of Education, 2010). The growth of online learning in higher education has been noted, particularly as institutions attempt to expand enrollments at a time of budget cuts and resource shortages. We have been approached by many organizations and individuals in multiple training settings to provide online teaching expertise. These include non-profits, corporations, and the U.S. military. In fact, online learning has grown in the university system itself.

This certificate addresses UH system needs. Potential program participants include individuals from military, corporate, educational, and health care institutions. Many participants may already have master's degrees and are seeking additional professional development or an update of skills. Many participants may also be in existing master's programs, including the Department of Educational Technology's (ETEC) Master's of Education in Educational Technology. In addition, many participants are current UH faculty desiring to learn to incorporate hybrid delivery models into their existing courses. The program provides significant professional development for members of its own institution.

Finally, the need for online teaching expertise extends beyond Oahu, where UHM is located, to the neighbor islands, especially where such programs have previously not been available. Because the courses will not only teach but also model distance education strategies by being online, the Certificate will be a statewide program. Thus, the program is expected to follow trends of current ETEC programs in expanding educational access across the state and successfully reaching underserved populations, including Native Hawaiians and Pacific Islanders.

The need and demand for online courses, both in K-12 and higher education, has increased because of the desire to make education accessible to all learners in a current economy that restricts travel, small class sizes, and specialized teachers. The Hawaii State Legislature recognized the importance of online teaching when it established the Online Task Force to review education policies, requirements, and oversight functions of the state to provide congruency and alignment with the needs and potential presented by online learning.

\section{Program History}

ETEC has offered a departmental based graduate COLT since summer 2009. Beginning in fall 2012, the program has been an officially recognized UHM graduate certificate and students have received recognition on their official transcript of program completion. The unofficial program allowed the department to test, evaluate, and refine the program ensuring its quality and student satisfaction with outcomes.

The demand for the certificate program fit the department's own assessment of why such a program was needed for K-12 and higher education instructors. Thus, we increased the number of courses on e-learning and developed a departmental, three-course sequence of existing courses as a pilot project. This program has continually attracted new students in the past 2 years despite a lack of publicity. Students who completed the sequence indicated a desire for a more formal credential and the ability to take advanced coursework. The pilot version allowed students to select a Basic proficiency (three courses with two required) or Advanced level (five courses with three required). The official certificate corresponds to the Advanced level and was the only one offered beginning in 2012.

The COLT program achieved formal approval from the UHM and began as an officially recognized graduate certificate program in Fall 2012. Students who had been taking courses in the departmental program prior to 2012 have applied for formal admission to the certificate and transferred courses already taken. All students admitted to the program complete a practicum and culminating project. The program will have its first certificate completers in Spring 2013. 


\section{Teaching and Tools}

All COLT courses are taught fully online and may be synchronous, asynchronous, or mixed; electives may be taught as hybrid courses with some face-to-face sessions. The courses are taught by experienced faculty in ETEC with research and teaching expertise in distance learning. While courses may use University-provided tools for delivery such as a course management system, online audio conferencing, or virtual worlds, instructors regularly incorporate new tools with an emphasis on free and open-source applications. All courses provide students with the opportunity to explore emerging technologies and to develop skills in researching and evaluating tools beyond those used in the courses. This is a benefit of the more flexible, experimental, and entrepreneurial model of the program.

Students are exposed to multiple methods of online pedagogy across the sequence of courses as a way to model best practices found in distance learning. All courses are by design student centered and project-based and provide significant opportunities for discussion, collaboration, and reflection. Moreover, the entire COLT program facilitates cooperation and community, helping to build a sense of belonging that is needed for establishing strong social presence. Courses are developed jointly by the ETEC faculty, reviewed regularly to examine the instructional methods used, and benchmarked against best practices in the field. The ETEC faculty all have a solid background in instructional design and apply these principals to course development and implementation. Individual courses are designed by faculty teams with a master plan for instructional strategies and goals described in the syllabus, with faculty members providing their own expertise in implementation and expected to adapt to the specific learning needs of the students in the class.

\section{Providing a Clearly Delineated Program Structure}

The COLT program is based on long-standing ETEC course offerings, which have received high ratings from students. All courses are part of the existing Master's degree in Educational Technology, which received accreditation from the National Council for Accreditation of Teacher Education (NCATE) Specialized Professional Association (SPA) through the Association for Educational Communications and Technology (AECT) in 2009.

The COLT graduate certificate is comprised of three 3-credit required courses, plus two additional 3-credit elective courses. The five courses are designed to cover a range of competencies to educate candidates in understanding, designing, and delivering online learning. The courses may also be used in elective sequences for other programs such as the master's or doctorate. Core competencies include: (a) theory- and research-based knowledge; (b) an understanding of tools and strategies; (c) assessment and evaluation; (d) understanding of ethical practice; and (e) practical application of theory, tools, and strategies in designing online environments.

\section{Making Individual Choices}

Students select two electives with approval by the COLT adviser, a tenured ETEC faculty member who coordinates the program. The electives may be chosen from among the rich array within the Department's graduate course offerings. Courses must relate to the overall goals of the certificate but are designed to meet the specific needs and objectives of the individual student. These courses provide more advanced application of the concepts covered in the required courses, and are expected to directly relate to successful completion of the capstone project in the final course, ETEC 632. While there are multiple options, several examples illustrate the possibilities.

For a certificate student working as an instructional designer in a higher education setting, electives might include ETEC 622: E-learning Theory and Design and ETEC 654: Programming for Games \& Simulations. For a certificate student working as a teacher within a Hawaii e-school setting, electives might include ETEC 641: Emerging Technologies for K-12 Teaching and ETEC 662: Assessment and Evaluation in E-learning. For a certificate student working as an educational technology coordinator in a school, electives might include ETEC 672: Distance Education Technology and ETEC 674: Instructional Technology Management. Finally, for a certificate student seeking a future job in a training setting, electives might include ETEC 652B: Authoring E-learning Environments: Computer-Assisted Instruction (CAI) and ETEC 692: Practicum in E-learning. 
A practicum or internship is not required. Internships may be offered and will be administered by the instructor teaching the capstone course or may be completed as one of the electives. Most students in the program are already employed in educational settings and are encouraged to apply their learning directly within their locus of control.

\section{Pulling It All Together}

Across the sequence of courses, students experience a variety of instructional techniques and tool applications, and in more advanced classes are expected to apply those in their own designs, which are assessed as part of the culminating project. Such an assessment provides at least one form of evidence that quality teaching models have provided a successful apprenticeship. As in most institutions, students also provide end-of-course evaluations and, while not explicit to instructional method, the high scores that consistently are above institutional averages suggest the instruction is effective and engaging.

While assessment is applied through each of the required and elective courses to ensure students are learning the fundamentals of online learning and reaching, the certificate program requires successful completion of a culminating, integrative experience by which students demonstrate mastery of design and implementation. This may be achieved through an internship, project, or electronic portfolio in which a student demonstrates mastery of program objectives, most typically by designing, developing, and evaluating a distance learning environment. The instructor in the capstone course supervises the culminating experience and assesses outcomes based on achievement of the requisite core competencies. Students are required to develop a formal presentation for an online international conference, the Teaching, Colleges, and Community (TCC) Worldwide Online Conference, to present the results of the project in a public and professional context. Capstone projects are reviewed by the full faculty as part of the department's program evaluation.

\section{CONCLUSIONS}

The idea that traditional higher education institutions represent a monolithic and antiquated format for learning is an oversimplification of a complex system that has evolved because learning is much more than exposure to content or experts. In fact, when Willingham (2009) wrote of why students are bored with school, a major problem is that insufficient attention is given to what is known about learning and human behavior. While this may suggest that change is needed in traditional education, it does not lead to the idea that new technology alone is the answer.

Critical success for innovative programs will be built on delivery models that take into account the peculiarities of human nature such as our gregarious desire for collaboration or cultural values such as Ohana, which in Hawaiian refers to the importance of extended family Relying on purely economic models that predict mass content delivery with minimal interaction may not provide the most successful outcomes nor serve the individual learning needs of students who desire learning beyond self-motivated, asynchronous systems.

Thus, in order for the most robust and successful models to be designed and delivered, innovative opportunities for flexible and experimental methods must be seized. Moreover, research must be conducted within these environments to comprehend and identify critical success factors. Although the university system at times can be rigid, finding opportunities for experimentation is key. New designs that combine what we know about learning, the brain, and newer technologies can provide successful learning environments assuaging the "sky is falling" fear generated by the understandable confusion that accompanies significant change.

\section{AUTHOR INFORMATION}

Dr. Michael Menchaca is an associate professor and coordinator of online programs in the Department of Educational Technology at the University of Hawaii. He specializes in online learning and has helped create and establish successful online programs at multiple institutions. He publishes research on online learning, social justice with technology, and integrating technology into teaching and learning. Dr. Menchaca has consulted for numerous schools, districts, and county and state offices. He has served as principal investigator for several state and federal 
grants. Dr. Menchaca was also an IT specialist for many years, specializing in network management. E-mail: mikepm@hawaii.edu (Corresponding author)

Dr. Ellen Hoffman is a professor in the Department of Educational Technology at the University of Hawaii. She is currently the department chair and also coordinates the department's doctoral specialization in educational technology program. She has over 15 years of administrative experience in higher education including directing grants and research centers. Dr. Hoffman's research interests include qualitative research methods, technology policy and standards, e-learning, digital libraries, digital literacy, and the scholarship of teaching. She has taught at every level from pre-school to post-secondary. She won the College of Education's Excellence in Teaching Award in 2008. E-mail: ehoffman@ hawaii.edu

\section{REFERENCES}

1. Adkins, S. (2009, October). Innovation in educational technology and the virtualization of K-12 and higher education. Webinar presented for Ambient Insight's Learning Technology Innovation series online at: https://sas.elluminate.com/site/external/event/description?instance id=15563

2. Anderson, J., Boyles, J. L., \& Rainie, L. (2012). The future of higher education. Washington, DC: Pew Internet \& American Life Project. Retrieved from http://pewinternet.org/Reports/2012/Future-of-HigherEducation/Overview.aspx

3. Abrami, P., Bernard, R., Bures, E., Borokhovski, E., \& Tamim, R. (2011). Interaction in distance education and online learning: Using evidence and theory to improve practice. Journal of Computing in Higher Education, 23(2-3), 82-103. doi: 10.1007/s12528-011-9043-x.

4. Center for Excellence in Higher Education. (n.d.). About U.S. higher education. Retrieved from http://cehe.org/facts-costs.html

5. Christensen, C. M., Horn, M. B., \& Johnson, C. W. (2008). Disrupting class: How disruptive innovation will change the way the world learns. New York, NY: McGraw-Hill.

6. Desantis, N. (2012, March 18). A boom time for education start-ups. The Chronicle of Higher Education. Retrieved from http://chronicle.com/article/A-Boom-Time-for-Education/131229/

7. Menchaca, M., \& Bekele, T. A. (2008). Learner and instructor identified success factors in distance education. Distance Education, 29(3), 231-252.

8. Merriam, S. B. (2008). Adult learning theory for the twenty-first century. New Directions for Adult and Continuing Education, (119), 93-98. doi: 10.1002/ace.309.

9. U. S. Department of Education. (2010). Transforming American education: Learning powered by technology. Washington, D. C.: Office of Educational Technology. Retrieved from http://www.ed.gov/technology/netp-2010

10. Willingham, D. T. (2009). Why don't students like school? A cognitive scientist answers questions about how the mind works and what it means for the classroom. San Francisco, CA: Jossey-Bass. 
NOTES 